\title{
On the Value Connotation of MOOC and Value Orientation of Development of Chinese MOOC
}

\author{
Zhaoyang Xu \\ The School of Public Affairs, University of Science and Technology of China, Hefei, China \\ Email: xzyxzy@mail.ustc.edu.cn
}

Received 9 December 2015; accepted 8 January 2016; published 14 January 2016

Copyright (C) 2016 by author and Scientific Research Publishing Inc.

This work is licensed under the Creative Commons Attribution International License (CC BY). http://creativecommons.org/licenses/by/4.0/

c) (i) Open Access

\begin{abstract}
In recent years, MOOC has developed rapidly in the world, and become the key power of promoting the modernization transformation of education cause, forcing the reform of traditional education system. This paper, using the thought of interpretivism, analyzes the value connotation of MOOC, including mean value and end value, and through combining national conditions puts forward four aspects of value orientation which should be adhered to for the development of "Chinese MOOC"- "timely help" on function position, combination of Chinese and Western on developing method, distinct personality on educational philosophy and flexible management on government regulation.
\end{abstract}

\section{Keywords}

MO0C, Mean Value, End Value, Value Orientation

\section{Introduction}

MOOC (Massive Open Online Course, MOOC for short), is a burgeoning online teaching form distinguished from traditional classroom teaching. There have been millions of registered users in MOOC platform since Canadian bachelors, George Siemens and Stephen Downes set up the first MOOC course, Connectivism and Connective Knowledge. Because of its high-speed spread and scale of effects, MOOC certainly becomes a dark horse in education in the information age, and is also a great impetus of reform of education system.

Recently, the practical exploration of MOOC has obviously surpassed theoretical research. When I search for some present studies on MOOC, I find most of them are mainly about MOOC's origins, characteristics and effects or research at the angle of learning system, but the philosophical reflection remains to be enriched. This 
paper tries to research the value connotation of MOOC from the angle of philosophy, which has multiple meanings in both theory and reality: first, it expands the study area of axiology, making axiology further application and verification in practice, which complies with the orientation of Marxist value; second, materialism indicates that the foundation of development of things is an internal factor that charges things' nature and developing direction. Therefore, the study of MOOC philosophical value is the inquiry and reflection of its rising reason. After further understanding, comprehending and using MOOC, it makes a difference to promote MOOC in China; third, researching the value of MOOC also contains real meaning of thought way. As the leap of science and technology, our lives turn into a trend of diversity. It is a request for us, as a society, to comprehend correctly societal diversity, to establish a good mentality and to keep a rigorous and inclusive style. At last, the study of axiology will lead modernized development of the education cause. The modernization transformation of education cause, as an important part of modernization construction goals, needs a hot debate of value urgently to guide the reform and innovation of education under information age.

This paper covers four chapters. The first one includes a brief introduction of the origin, development, research status of MOOC, and the theoretical and practical meaning of this paper, as well as the full text structure. The second expounds the philosophical explanation of value, coordinately discussing the value connotation of MOOC under the guidance of Aristotle's value classification. The third, as the main body, starts with ideals of MOOC and classified discussion of various expressions of value connotation of MOOC, in order to indicate the necessity of Chinese MOOC. The last, by considering the difference of education background between China and countries such as the USA where MOOC has already grown and matured, concludes four suggestions on value orientation of Chinese MOOC in the future with an expected impetus to the reform of our education.

\section{Value and Value Connotation of MOOC}

\subsection{The Philosophical Explanation of Value}

Axiology, coordinate with ontology and epistemology, is one of the three basic theories (meta-theory) in philosophy. The issue of value, simply complies with the meaning (good and bad, good and evil, beauty and ugliness, pros and cons, weal and woe, and so on) of everything (including things, humans and society, thought and activities of humans) for humans, and related reflections and selections of humans [1]. To obtain value is the fundamental intension for humans' subjective initiative and creativity.

"Value", as a vital notion in Marxist dialectical materialism epistemology, includes three aspects of connotations as follows:

First, value embodies a kind of "relation state" existing between subject and object. For humans, there are two basic activities, understanding and improving the world. Thus, understanding relation and practice relation also form the elementary relation between subject and object. Throughout understanding and practice activities, subject, at its demand, selects, uses and even improves object, oppositely object may satisfy subject's demand with its function, profile and characteristics. The relation between subject demands and object attributes above is exactly the relation of value between subject and object [2].

Second, value contains dual attributes, subjectivity and objectivity. It is the meaning of existence of object for subject, and a natural relation behind all humans' objective activities. Neither the axiology of objective idealism which abandons the subjectivity of value, nor the axiology of subjective idealism which abandons the objectivity of value, is an unfair theoretical point.

Third, value is positive and negative. Only when the existence and attribute of object is positive to the demand of subject, it is considered with positive value, valuable for short. On the contrary, it is deemed to have negative value.

\subsection{The Value Connotation of MOOC}

Due to multi-angle and multifaceted demands when object satisfies the survival, development and improvement of subject, the relation of value between subject and object is very rich and the classification of value is the same. Max Scheler, a German philosopher, sorted value into four levels: sensate value, value of life, spiritual value and religious value [3]. American philosopher, E.S. Brightman, divided value into value of itself and tool, permanent and temporary value, general and personal value, high and low value. Otherwise, Chinese scholars prefer material value, spiritual value and human value. In general, the most acceptable classification today still comes 
from the ancient Greek philosopher, Aristotle. He divided value into mean value and end value: "End” restricts the direction of value, and "mean" fulfills the purpose of value. Both of them are necessary. This sort is not only easy to use, but conduces to judging and balancing value before making a correct selection [4].

Conducted by Aristotle's method, mean value and end value, we do the value analysis of the new favorite in education, MOOC. The mean value of MOOC embodies the value of MOOC teaching style for education, and value-in-use. The end value of it is however for the subject, the same as "human value". Online videos, questions, forums and so on, as specific carriers of MOOC, give students an intuitive and perceptual impression. And all of them serve students in different steps, clear non-intelligence factors in education, and to a great extend improve educational environment including educational process optimization, teaching efficiency increase and educational scale expansion. The end value of MOOC, different with the mean value on teaching process, concentrates on the fundamental issue of education activities- education for man and improvement of student's mind. MOOC as an education method whose ultimate value is "freedom" and "liberation", liberates people from fatuity, ignorance, vulgarity, prejudice, fallacy, obstinacy and greed and makes people think for themselves, do themselves and be themselves [5]. Without humans without value, so the value orientation and home of MOOC is human all-round development, emancipating and freeing the mind.

Therefore, the value expression of MOOC is not limited to a single value. One-sidedness comes after inspecting value in one certain dimension. Instrumental rationality only pays attention to mean value, the function of MOOC in education system. Likewise, emphasizing human but restricting the basic function of MOOC in education, the end value of MOOC is nonsense.

\section{Value Expression of MOOC}

\subsection{Ideals of MOOC}

Modern universities start from the first Industrial Revolution. Standard education mode, content of courses and test form created standard talents in the industrial age. Unfortunately, disadvantages in that education mode stood out, as the "third Industrial Revolution"1 came, such as unfair distribution of education sources, lack of creativity and structural unemployment of graduates, which have been a bottleneck of modern society, forcing the reform of traditional education cause.

Nowadays, human society steps into a new age, in which internet technology almost changes the mode of production. Education, a key link of knowledge teaching and talents cultivation, is also pushed into an "online" age. But contrasting with briefly-appeared network schools, MOOC transfers main purpose of education from "teaching" to "learning", promoting an idealism education goal that anyone anytime anywhere can learn any knowledge [6]. "Anyone" means that there is no limitation of ages, races, status, positions, families and amounts. "Anytime anywhere" breaks the block of time, areas and cultures. In a coffee house or at the desk, you can learn whatever you want through a network cable. "Any knowledge" covers courses from all kinds of domains. Where there is knowledge, there is MOOC. Regardless of academic theories, professional practice knowledge and something you are interested in, MOOC is there for you.

Though the influence of MOOC is still limited, even like an infant, it should be attached importance to on the subversion of conventional education, the reform of talents cultivation and influence of comprehensive national strength.

\subsection{Mean Value of MOOC}

\subsubsection{Increasing Educational Benefit}

The chairman of EdX, Anant Agarwal, when accepting the interview of Guangming Daily, put forward a formula, educational quality/educational cost = educational benefit [7]. First, coming to educational quality, MOOC has collected best educational resources in different areas to compile high-level courses, and then publishes them on the internet. In that way, high quality educational resources are easy to be accessed, frontline teachers are encouraged to improve own teaching levels, which makes a difference to national education quality. Second, about the educational cost, after recorded, the cost will not increase no matter how great the scope of

\footnotetext{
${ }^{1}$ Jeremy Rifkin, “The Third industrial Revolution”. The third industrial revolution refers to a new age when digital production, new energy
} and materials are widely used. 
students is. That is to say, the marginal cost is nearly zero. The productivity of such "non-scarce marginal products" ${ }^{2}$ is totally determined by demand, demand is productivity [6]. When students' amount reaches to a degree, cross correction contributes a lot to the reduction of management cost, even raises the subjective initiative and optimizes interaction and experience. As you see above, MOOC is able to popularize high quality educational resources and universalize rare resources, under an extremely low cost [6].

\subsubsection{Reforming Educational Mode}

There are many problems in conventional mode: First, students cannot choose courses and teachers personally, due to the limitation of teacher resources and enrollments. Second, teaching is the main activity in class, as a result, students are learning passively. Interests and effects are in a low condition. Third, teachers giving lessons in a same progress on class and so much work after class reduce the attention on individual student, which causes the problem of polarization. Fourth, it is hard for students to pay full concentration on class in 40 to 45 minutes, leading to the waste of educational resources. The establisher of Khan College, Salman Khan said, "Conventional pedagogy is inhumane”. MOOC transforms conventional educational structure and mode and reforms the function of teacher and students. Students arranged with all educational resources and activities become the true subject of learning. Active learning, self-paced schedule and self-selected courses all come true. These stimulate students learning what they are interested in and feeling the way to learning. Meanwhile, MOOC, a joint of many world famous top colleges, attracts a lot of colleges and universities to establish some massive online courses platforms. Students have a new way to select schools, teachers and evaluations as per their own knowledge base, interests, and demands for the purpose of individualized learning schedule. Furthermore, MOOC divides every course into several knowledge points, 10 to 15 minutes per point. It is shown that the most efficient video for learning is less than 15 minutes [6]. Mini-test and time-limited task are enclosed after every course. "Short video, mini-test, time-limited task", is conducive to maximizing the teaching contents.

\subsubsection{Promoting Equity in Education}

Inequity commonly appears in many countries, owing to historical problems, different natural conditions and unbalanced economic development. More than two thousand years ago, the ancient thinker and educator, Confucius put forward "education without distinction". In ancient Greek, the philosopher Plato and his disciple Aristotle also declared everyone had a right to receiving education. From this, pursuing equity in education is one of the oldest ideas in human society. Educational equality is a cornerstone of social equality, and the development of education cause essentially determines the national fate. Report to the $18^{\text {th }}$ national congress pointed out "Promoting greatly equity in education, distributing reasonably educational resources" in 2012, which attracted much attention in society. As we see, educational equality consists of equal opportunity, progress and quality. Over the last one hundred years, most of countries have reached this target, equal opportunity and progress, throughout all kinds of education institutes and regulations and policies. However, the education quality between city and country, different areas still remains in some regions. MOOC breaks the knowledge barrier of colleges, more people having access to high quality educational resources. Everyone, to some degree, can watch world-class courses only needing a network cable. As for hardware gap, the Third Plenary Session of the $18^{\text {th }}$ Central Committee indicated: "Building a valid mechanism of expansion of high quality education resources with information methods to reduce the gap between areas, city and country, colleges" [8]. Ministry of education also commanded: Internet will basically cover all kinds of schools with online learning equipment in 2015, including 50\% of broadband access rate [9]. As the reduction of digital gap and popularization of elite education, equity in education is promoted at the same time.

\subsubsection{Impulsing Educational Research}

Conventional on-site teaching restricts the educational research, because of complexity of individual behavior and measurement problem. MOOC is the new dawn of educational research. With the development of cloud storage and cloud computing, big data is recorded, stored and analyzed efficiently. All of online learning behavior recorded in digital makes a great difference to educational research. On the one hand, students directly know what they learn or how to arrange time through big data so that learning will be more efficient. On the other hand, teachers with analyzing big data are able to trace the progress of teaching and students' problems in

\footnotetext{
${ }^{2}$ Professor Wang Jianguo in Perking University, defined, one produced with a fixed cost, duplicated infinitely without extra cost, is called a
} non-scarce marginal product. 
learning, in order to keep the teaching level. In addition, theories of education will be under the test of big data. It is obvious that some of them may be verified, improved or reread, and some may disappear in history. New educational theories may also spring out at the same time.

\subsection{End Value of MOOC}

\subsubsection{Encouraging Innovations, Cultivating Self-Learning Ability}

"Why do our universities always fail to produce excellent talent?” It's known as asking of the Qian Xuesen that is deeply sticking every educator and is the challenge to our current education. Cheng Fangping, a researcher from the Central Education and Research Institute, pointed out that in any times, outstanding talents born with individual thinking, exploring and pursuing spirits, manage to find out and resolve problems [10]. What is unfortunately, our current education imprisons the innovation and divergent thinking of students using the "standard keys". Education is to cultivate talents for future that appeals to innovated talents. Comparing to traditional process "serial producing” "formatted” graduates, MOOC allows students to choose courses and progress according to own knowledge base, interests, and demands, no matter where and what you want to learn. As a Chinese proverb says, "give a man a fish and you feed him for a day". No one knows which skill needs in the future, but what is more significant is to master the method of learning.

\subsubsection{Establishing the Concept of Lifelong Learning, Building Learning Society}

French educational thinker Edgar Faure, worked for UNESCO, his “Learn to survive” emphasizes two concepts, lifelong learning and learning society, called a milestone in contemporary educational thought. From that time, it has been accepted all around the world, becoming a great goal in social process. Nowadays the world changing beyond everyone's imagine, new problems and challenges rising anytime, "Never too old to learn" tends to be a common life style. MOOC cleans most of blocks of non-educational factors and frees students from cram learning. So learning comes back to itself and learning society gets a great progress.

\subsubsection{Broadening International Vision, Enhancing International Competitiveness}

With the deepening of globalization, the complex and openness of social system is up to a high level, challenging the students on knowledge and thought. Learners through MOOC broaden their international vision and enhance individual competitiveness when managing scientific knowledge. In colleges and universities, developing high quality MOOC also becomes a core way to improve self-competitiveness, because first-line teaching leaps to a core status. As for nation, comprehensive strength competition is talents competition, also education competition. In the arena of the world education cause, MOOC is a key opportunity to present national cultural competitiveness apart from educational methods. The vice-president of SJTU, Professor Huang Zhen announced, "In the face of the global high-quality educational resources and strong cultures, Chinese universities must accelerate education reform and improve teaching quality, otherwise there is a danger of becoming world-class labs” [6]. It is both an opportunity and challenge so that MOOC should not be neglected.

Moreover, MOOC is leading global cultures to a win-win situation in a collision. It is not only a carrier of knowledge, but is vital cultural strategy resources. Colleges and universities share high quality educational resources, which is kind of communication, also competition of different cultures in the world, and perhaps is a hope way to mutual respect of human civilization in $21^{\text {st }}$ century [11].

\section{Value Orientation of Development of Chinese MOOC}

Value orientation belongs to value philosophy, Ms. Ye Lan gave a definition to it. She thought value orientation, a reflection of knowledge for objective things and own demand [12], controlled the practical activities of subject. Different objects may select corresponding value orientations to guide their practical way in the future.

Value orientation of education is the soul of educational reform [13]. Understanding and learning MOOC' growing process in north America makes sense, but meanwhile blind Occidentalism is not a scientific attitude, even brings in opposite effects to our education cause.

Therefore, the value orientation of Chinese MOOC with accordance to our educational condition and the time is of great importance to the modernization transformation of education cause. There are four suggestions below for value orientation of Chinese MOOC. 


\subsection{Value Orientation of Function Position-Set up a Timely-Help MOOC for China's Education}

Under the condition that the education system in the USA not only integrates together, but also keeps a balanced development in each section and field, Harvard, MIT, Yale and world-class courses have been released in American MOOC for the urgent thirst to top courses in America and around the world. But for China, when facing to the popularization and balance of education, timely help may be more effective than icing on the cake. For instance, Chinese MOOC had better release high quality applied courses to decrease the great number of unemployed people every year and to adjust the structure of employment.

\subsection{Value Orientation of Development Method-Combine Localization and Internationalization.}

Along with economical globalization, education system is also involved in the diversity trend. Chinese MOOC needs to keep pace with the trend to make own nationality, independence and uniqueness flourish. For admitting the differences among areas and combining educations with characteristics, keeping both localization and internationalization, China needs a developing way of MOOC with Chinese characteristics [14].

\subsection{Value Orientation of Educational Philosophy—Share High Quality Resources and Distinguish Personality of Schools}

Different histories and cultures of institutes create different teaching styles. Sustainable development of China's education depends on exact goals of institutes as per their types, missions and advantages, grasping the chance of MOOC trend to highlight our efficient teaching characteristic and ability, trying our best to make our education stay in the state "owning what others do not have and owning what better than others”. As Heidegger said, technology is not only a mean, but an expression method, a combination of nature, world and human [15]. The period of educational transformation pushed by MOOC refers to a chance to enhance reputation and words power, and a challenge that is destined to be overcome by our colleges and universities.

\subsection{Value Orientation of Government Regulation-Insist on Flexible Management}

Technology is not only a tool, but also a power of reshaping the society. The reform of education system involves national interests on all sides, is a totally global one under instruction of governments. Competent authorities should think forward, urgently introduce some policies on guiding thought, framework principle, global layout and policy making related to MOOC. Moreover, to handle intellectual property, data copyright and such sensitive problems, previous preparation is necessary. All in all, MOOC is a newborn education pattern. In China, it is even in an exploring period. Strict and hard management may strangle it in the bud. Therefore, government should insist on flexible management, encourage and cultivate the new education method.

Currently, MOOC, the new trend of the internet education, has already been one of the main forces to promote the reform of education in different countries around the world. China, as an important part in the world, should not and cannot avoid the reform. Therefore, China needs to accept MOOC and to cultivate it in a flourishing growth with Chinese characteristics. It is the only way to improve Chinese education quality and reach to the world's most advanced level.

\section{References}

[1] Li, D.S. (2000) The Value of Axiology Research. Searching Truth, 6, 5-8.

[2] Yuan, G.R. (1985) Value and Cognition. Journal of Beijing Normal University, 3, 47-57.

[3] Zhang, M. (2011) Research of Scheler’s Value. Hubei University, Wuhan.

[4] Jiang, C. (2000) On the Foundation, Connotation and Structure of Value. Jianghan Tribune, 7, 52-56.

[5] Barnett, R. (2013) Concept of Higher Education. Peking University Press, Beijing.

[6] Tang, M. (2015) The Revolution of MOOC. China CITIC Press, Beijing

[7] Deng, H. (2013) Facing up to MOOC, One Is Courage, Another Is Innovation for China's Universities-Interview the Chairman of EdX, Prof. Anant Agarwal. Guangming Daily. 
[8] Information Office of the State Council of the People’s Republic of China. (2013) Decision of the Central Committee of the Communist Party of China on Some Major Issues Concerning Comprehensively Deepening the Reform.

[9] Ministry of Education of the People’s Republic of China (2015) Working Points for Informatization Education in 2015.

[10] Cheng, F.P. (2009) Mass Production Cannot Make Education. People’s Daily.

[11] Sang, X.M. (2013) A Cultural Strategic Interpretation of Steve Jobs’s Question: Exploring the Trends of Online Course Development. Open Education Research, 3, 30-41.

[12] Xue, Z.X. (2009) A Research Summary of Our Education Orientation in Recent 20 Years. Educational Science Research, 11, 21-23.

[13] Feng, J.J. (2009) Moving towards to the Liberation of People-Recalling the Development Process of China's Education in 30 Years of Reform and Opening up. Journal of Higher Education, 1, 17-25.

[14] Liu, H.H. (2014) Impacts of MOOC on Higher Education-On the Angle of Core Value Orientation of Higher Education. Journal of Anhui Normal University, 4,517-521.

[15] Xu, L. (2008) On the Value Load of Technology. Journal of Shandong University of Science and Technology, 6, 10-13. 